\title{
Minimally invasive surgery of humeral fractures with posterior approach and anatomical plate
}

\begin{abstract}
We evaluate the functional and radiological outcomes, the union rates and functional results in a group of patients with diaphyseal fracture of the humerus of the distal third with a minimally invasive technique whit posterior approach and anatomical plate. Between 2013 and 2017, 32 patients were operated, with an average age of 31 years. Functional assessment was performed using the abbreviated DASH functional scale and pain was classified according to the VAS scale.

All the fractures healed successfully, except for two cases that presented in union delay. The radial nerve injury prior to the intervention was recovered progressively without requiring transfers. The functional results were satisfactory in the patients who completed more than one year of follow-up. The posterior approach of the minimally invasive surgery in the treatment of this particular fracture pattern seems to show a biological advantage by allowing complete union rates in all patients. The iatrogenic injury of the radial nerve does not seem to increase in relation to its isolation and protection in the proximal portion of the triceps Level of evidence: IV
\end{abstract}

Keywords: humerus fractures, minimally invasive approach, posterior approach, anatomical flocking plate
Volume I2 Issue 4 - 2020

\author{
Carlos Arroyo Sánchez, César Abril, \\ Anderson David, Guillermo Varón \\ Orthopaedic Trauma Surgeons, Santander University Hospital, \\ Colombia \\ Correspondence: Carlos Arroyo Sánchez, Orthopaedic
Trauma Surgeons, Santander University Hospital, Bucaramanga,
Colombia,Tel +57 312325 I248, Email caarroos@hotmail.com
}

Received: January 27, 2020| Published: July 24, 2020

\section{Introduction}

Diaphyseal humerus fractures belong to 3 to $5 \%$ of fractures in general. ${ }^{1,2}$ Diaphysis engagement in its middle third is the most common with around $60 \% .{ }^{1}$ Fractures with compromise of the distal third of the diaphysis have an $10-48 \%$ of incidence. ${ }^{1,3}$ Surgical treatment of this subgroup of fractures has shown good functional results on the Bickel-Perry scale when compared with non-operative treatment, reporting excellent and good outcomes. ${ }^{4}$ The rates of union seems to be higher in the surgical treatment compared with the nonsurgical treatment, the last has an increasing in the rate of non-union up to six times..$^{5,6}$

Previous papers has shown the benefit of minimally invasive techniques in surgical treatment in terms of safety, functional results and biological advantages. ${ }^{6-8}$ Within the minimally invasive surgical approaches used, we found the anterior and lateral approach. ${ }^{9}$ The posterior approach has been indicated in the treatment of fractures close to the olecranon fossa allowing a greater location of screws in the distal portion of the plate, generating greater stability. However, we consider that the application of straight plates can generate difficulties in the location of multiple distal screws and it is technically difficult to bend the implants. We present an evaluation of the clinical and functional results in a series of cases of patients with fractures of the distal humeral shaft treated with distal extraarticular anatomical humerus plate with a posteriorly minimally invasive approach.

\section{Methods}

Between the years 2013 to 2017, 32 patients with a diaphysial fracture of the humerus located in its distal third were included in the case series.

The inclusion criteria for treatment with this technique were:

Fractures proximal $6 \mathrm{~cm}$ from the olecranon fossa; fractures AO 12 A 1.3, 2.3 and 3.3. AO 12 B 1.3, 2.3 and 3.3 and $\mathrm{AO} 12 \mathrm{C} \mathrm{3.1,3.2} \mathrm{and}$ 3.3. Damage of the soft tissues in the anterior surface of the arm. We also included patients fractures with unacceptable angulation in varus or valgus, associated or not with radial nerve injury.

Patients affected with distal humerus articular traces, under 18 years old, pathological fractures, poor state of soft tissues in the posterior aspect of the arm, those who underwent an open posterior approach and those who did not tolerate the prone position were excluded. All patients were informed about the surgical technique and accepted their surgery consent.

A data collection form was used to record sociodemographic, clinical and follow-up variables. The operative notes were evaluated to locate the specific data describing the injury and surgical technique and radial nerve injury. Shoulder and elbow range of motion (ROM) were measured in the office by the treating surgeons with goniometry. The pain was value with the visual analogue scale (VAS). The QuickDASH (Disabilities of Arm Shoulder and Hand) functional score was applied in its version adapted to Spanish.

\section{Surgical technique}

The patient was located in prone position with a support in the middle third of the affected arm. The anatomical landmarks are: olecranon, lateral epicondyle, medial epicondyle, radial nerve, ulnar nerve. A first incision was made between the lateral column and the olecranon fossa, two centimeters proximal from the lateral lateral epicondyle making a lateral window to expose the distal humerus. Then a skin mark is made with the plate to make the proximal incision (Figure 1). A $3 \mathrm{~cm}$ proximal incision is made in the posterior arm , the radial nerve its exposed between the long portion of the triceps and the posterior edge of the deltoid, is repaired with a vessel loop to avoid its compression during the plate fixation. An LCP anatomical extraarticular $3,5 \mathrm{~mm}$ plate (Depuy Synthes) is it slipping retrograde from distal in the lateral epycondile placing it below the radial nerve. Reduction of the fracture is made with axial traction and compression maneuvers verified by fluoroscopy. We put the first screw in the distal portion of the plate on the lateral column; and then we put the first 
proximal screw achieving the alignment in the anteroposterior plane avoiding distal displacement. Once the reduction of the fracture and optimal plate location are confirmed, the distal screws are fixed, alternating with proximal screws until a minimum of six corticals proximal and distal. Finally, the reduction was verified by fluoroscopy.
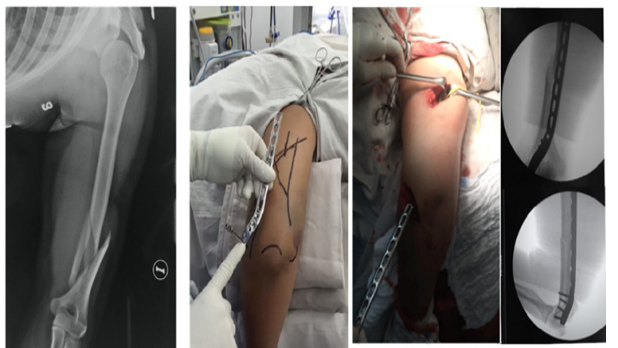

Figure I Humeral fracture fracture due to horse fall. Note the landmarks and approach maneuver with dissection of the radial and distal nerve over the lateral epicondyle. Sliding of the plate and revision of the reduction by fluoroscopy.

In case of a radial a radial nerve injury in a closed fracture, no routine exploration was performed in the proximal portion, except in cases of exposed fracture where it was necessary at the time of debridement to determine the interposition of the radial nerve. A soft brachiopalmar immobilization and a palmar hand splint were applied in cases where the nerve was injured. The clinical control was carried out at two weeks, the second month, the fourth month and the postoperative year. Rehabilitation was started at the second postoperative week (Figure 2).

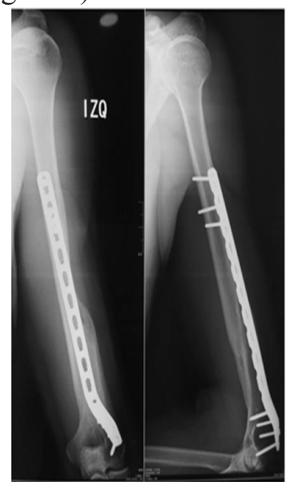

Figure 2 Postoperative X-Ray in 12 weeks.

Table I Demographics and radiological values

\begin{tabular}{|c|c|c|c|c|c|c|c|c|c|}
\hline Case & Age & Gender & Mechanism & AO & Open fracture & Complications & Union time weeks & Alignment & $\begin{array}{l}\text { Follow up } \\
\text { months }\end{array}$ \\
\hline I & 30 & M & Car Accident & I2A2.3 & No & Praxia Radial & 12 & $2^{\circ}$ & 12 \\
\hline 2 & 78 & $\mathrm{~F}$ & Fall & I2CI.I & No & No & 12 & $0^{\circ}$ & 14 \\
\hline 3 & 23 & $\mathrm{~F}$ & Carr Accident & $\mid 2 \mathrm{AI} .3$ & No & No & II & $1^{\circ}$ & 18 \\
\hline 5 & 17 & M & Fall & $|2 \mathrm{~A}| .3$ & No & No & 12 & $2^{\circ}$ & 12 \\
\hline 6 & 29 & M & Fall & I2A2.3 & No & No & 12 & $4^{\circ}$ & 18 \\
\hline 7 & 49 & M & Car Accident & $12 C 3.3$ & No & No & 12 & $2^{\circ}$ & 24 \\
\hline 8 & 30 & $\mathrm{~F}$ & Car Accident & $|2 B| .2$ & No & No & 10 & $5^{\circ}$ & 12 \\
\hline 10 & 23 & $M$ & Fall & $|2 B| .3$ & No & No & 10 & $2^{\circ}$ & 12 \\
\hline
\end{tabular}

\section{Results}

The mean age was 31.5 years (range 17-78, $\mathrm{SD}+/-14.9$ ). $65 \%$ were male and $35 \%$ female. According the trauma mechanism, the traffic accident was the most common with 14 cases, followed by 13 falls, gunshot wounds in four and the work accident in one case (Table 1).

The fracture was closed in 27 cases and open in five. The classification of the exposed fractures was made according to GustilloAnderson were presenting a case of type II, three of type IIIA and one of type III C.

The duration of the surgical procedure had an average of 76 minutes with a range of 60 to 120 minutes. The mean follow-up was 13,5 months with a range of 12 to 24 . Radial nerve injury prior to surgery was present in eight patients out of $32(25 \%)$, classified as a neurapraxia. The totality of patients recovered the function of the radial nerve in an average of 6 months.

Three patients presented other fractures associated between facial fractures, one case of poly trauma with fractures of the femur and distal radius and one case presented burns in the anterior region of the affected arm. The mean union rate was 12.1 weeks with a range of $10-$ 20 . There were no cases of non-union or reintervention. The average alignment in the anteroposterior axis was $2^{\circ}$.

Regarding the complications, three cases showed delayed union, two of them consolidated successfully at 16 weeks and the other case at 20 weeks without requiring reinterventions. One case presented praxia of the radial nerve in the postoperative period, which was recovered six months after the postoperative period. One case presented postoperative pain at the surgical site without requiring removal of the hardware one case presented a localized cellulitis associated with burns in the anterior region of the arm handled with antibiotic treatment. There were no cases of infection of the operative site off loss of fixation. Heterotopic ossification occurred in one case without impaired functionality.

All patients were fully evaluated one year after surgery. The mean elbow flexion was $124^{\circ}$, the average extension of the elbow was $3^{\circ}$. The mean shoulder flexion was $150^{\circ}$. On the VAS score scale, the average was 1 with a range of 0 to 6 . The average of the abbreviated DASH score was 11(Range 0-25). 
Table Continued...

\begin{tabular}{|c|c|c|c|c|c|c|c|c|c|}
\hline Case & Age & Gender & Mechanism & AO & Open fracture & Complications & Union time weeks & Alignment & $\begin{array}{l}\text { Follow up } \\
\text { months }\end{array}$ \\
\hline II & 46 & $\mathrm{~F}$ & Car Accident & $12 \mathrm{~A} 2.3$ & No & No & 12 & $1^{\circ}$ & 12 \\
\hline 12 & 31 & $M$ & Gunshot & 12B3.3 & IIIA & No & 10 & $3^{\circ}$ & 14 \\
\hline 13 & 26 & $M$ & Car Accident & $12 C 3.3$ & II & No & 12 & $0^{\circ}$ & 16 \\
\hline 14 & 32 & $M$ & Gunshot & $|2 B| .3$ & IIIA & No & 10 & $3^{\circ}$ & 18 \\
\hline 15 & 24 & $M$ & Gunshot & $12 C 3.3$ & IIIA & No & 11 & $4^{\circ}$ & 12 \\
\hline 16 & 22 & $\mathrm{~F}$ & Car Accident & $12 \mathrm{~B} 2.2$ & No & No & 11 & $0^{\circ}$ & 12 \\
\hline 17 & 54 & $M$ & Car Accident & I2B3.3 & No & Pain & 10 & $3^{\circ}$ & 12 \\
\hline 18 & 55 & $M$ & Car Accident & 12B3.2 & No & Delay & 16 & $2^{\circ}$ & 24 \\
\hline 19 & 22 & $M$ & Car Accident & $12 C 3.1$ & No & No & 12 & $5^{\circ}$ & 12 \\
\hline 20 & 48 & $M$ & Car Accident & $|2 B| .2$ & No & No & 10 & $4^{\circ}$ & 22 \\
\hline 21 & 41 & $\mathrm{~F}$ & Fall & $|2 A| .3$ & No & No & 11 & $3^{\circ}$ & 12 \\
\hline 22 & 37 & $\mathrm{~F}$ & Car Accident & $12 \mathrm{Cl} .3$ & No & No & 12 & $0^{\circ}$ & 18 \\
\hline 23 & 34 & $M$ & Car Accident & $\mathrm{I} 2 \mathrm{Cl}$ & No & delay & 18 & $3^{\circ}$ & 16 \\
\hline 24 & 56 & $\mathrm{~F}$ & Fall & 12B3.3 & No & Praxia Radial & 12 & $2^{\circ}$ & 12 \\
\hline 25 & 34 & $\mathrm{~F}$ & Fall & $12 C 2.2$ & No & No & 11 & $3^{\circ}$ & 12 \\
\hline 26 & 28 & $M$ & Fall & $|2 B| .3$ & No & No & 10 & $2^{\circ}$ & 14 \\
\hline 27 & 33 & $M$ & Car Accident & $12 C 2.2$ & No & No & 12 & $5^{\circ}$ & 12 \\
\hline 28 & 22 & $M$ & Fall & $12 \mathrm{~A} 2.3$ & No & No & 11 & $4^{\circ}$ & 12 \\
\hline 29 & 30 & $M$ & Fall & $12 \mathrm{~B} 2.2$ & No & No & 12 & $2^{\circ}$ & 12 \\
\hline 30 & 28 & $M$ & Car Accident & 12B2.3 & No & No & II & $5^{\circ}$ & 12 \\
\hline 31 & 29 & $\mathrm{~F}$ & Fall & $|2 B| .2$ & No & No & 12 & $3^{\circ}$ & 12 \\
\hline 32 & 21 & M & Car Accident & $12 C 2.3$ & No & No & 12 & $2^{\circ}$ & 12 \\
\hline
\end{tabular}

Table 2 Functional outcomes

\begin{tabular}{llllll}
\hline Case & Elbow flexion & Elbow extension & Shoulder flexion & Quick DASH & VAS \\
\hline 1 & $120^{\circ}$ & $0^{\circ}$ & $150^{\circ}$ & 20 & 2 \\
2 & $130^{\circ}$ & $5^{\circ}$ & 160 & 16 & 4 \\
3 & $130^{\circ}$ & $0^{\circ}$ & $120^{\circ}$ & 9 & 0 \\
4 & $130^{\circ}$ & $5^{\circ}$ & $170^{\circ}$ & 9 & 0 \\
5 & $120^{\circ}$ & $0^{\circ}$ & $120^{\circ}$ & 9 & 3 \\
6 & $130^{\circ}$ & $5^{\circ}$ & $150^{\circ}$ & 9 & 3 \\
7 & $125^{\circ}$ & $20^{\circ}$ & $130^{\circ}$ & 7 & 0 \\
8 & $150^{\circ}$ & $0^{\circ}$ & $160^{\circ}$ & 7 & 0 \\
9 & $135^{\circ}$ & $0^{\circ}$ & $150^{\circ}$ & 20 & 0 \\
10 & $130^{\circ}$ & $0^{\circ}$ & $160^{\circ}$ & 0 & 2 \\
11 & $130^{\circ}$ & $0^{\circ}$ & 150 & 3 & 0 \\
12 & 120 & $10^{\circ}$ & $160^{\circ}$ & 7 & 1 \\
13 & 120 & $0^{\circ}$ & $150^{\circ}$ & 12 & 1 \\
14 & 130 & 0 & $140^{\circ}$ & 9 & 11 \\
15 & 130 & 5 & 150 & & 0 \\
\hline
\end{tabular}

Citation: Sánchez CA, Abril C, David A, et al. Minimally invasive surgery of humeral fractures with posterior approach and anatomical plate. MOJ Orthop Rheumatol. 2020;12(4):80-84. DOI: 10.15406/mojor.2020.12.00523 


\begin{tabular}{|c|c|c|c|c|c|}
\hline Case & Elbow flexion & Elbow extension & Shoulder flexion & Quick DASH & VAS \\
\hline 16 & 122 & 0 & 150 & 7 & 1 \\
\hline 17 & $110^{\circ}$ & $20^{\circ}$ & $150^{\circ}$ & 24 & 6 \\
\hline 18 & $130^{\circ}$ & $5^{\circ}$ & $150^{\circ}$ & 9 & 1 \\
\hline 19 & $120^{\circ}$ & $0^{\circ}$ & $160^{\circ}$ & 11 & 1 \\
\hline 20 & $130^{\circ}$ & $10^{\circ}$ & $150^{\circ}$ & 12 & 0 \\
\hline 21 & $120^{\circ}$ & $5^{\circ}$ & $160^{\circ}$ & 7 & 2 \\
\hline 22 & $130^{\circ}$ & $0^{\circ}$ & $150^{\circ}$ & 9 & 1 \\
\hline 23 & $120^{\circ}$ & $5^{\circ}$ & $130^{\circ}$ & 11 & 1 \\
\hline 24 & $120^{\circ}$ & $10^{\circ}$ & $140^{\circ}$ & 13 & 0 \\
\hline 25 & $130^{\circ}$ & $5^{\circ}$ & $150^{\circ}$ & 15 & 2 \\
\hline 26 & $130^{\circ}$ & $10^{\circ}$ & $140^{\circ}$ & 11 & 1 \\
\hline 27 & $130^{\circ}$ & 0 & $150^{\circ}$ & 7 & 0 \\
\hline 28 & $120^{\circ}$ & $0^{\circ}$ & $160^{\circ}$ & 9 & 1 \\
\hline 29 & $130^{\circ}$ & $5^{\circ}$ & $150^{\circ}$ & 11 & 0 \\
\hline 30 & $120^{\circ}$ & $10^{\circ}$ & $150^{\circ}$ & 21 & 1 \\
\hline 31 & $130^{\circ}$ & $0^{\circ}$ & $150^{\circ}$ & 7 & 0 \\
\hline 32 & $130^{\circ}$ & $5^{\circ}$ & $140^{\circ}$ & 11 & 0 \\
\hline
\end{tabular}

\section{Discussion}

Surgical treatment for diaphyseal fractures of the distal humerus in its distal portion is the management standard5. Minimally invasive techniques have been gaining popularity, allowing the avoiding extensive dissection and disruption of vascularity and access to the fracture site, showing adequate functional outcomes. ${ }^{6-12}$

Gallucci et al. ${ }^{10}$ their series of 15 patients using a minimally invasive posterior approach reported successful union rates in $100 \%$ of the patients and a case of radial nerve apraxia that recovered completely, however, most patients presented fractures of the middle third. Ziquan $^{12}$ evaluated the functional outcomes in a group of 13 patients with fractures of both the middle and distal third of the Humeral shaft and a minimally invasive technique through the anterior approach, finding union in $100 \%$ of the cases without presenting radial nerve palsy associated with the surgical technique. Balam et al. ${ }^{13}$ Show a series of 37 patients with fractures of the distal diaphysial humerus and of the middle third with a minimally invasive technique by posterior, presenting complete union rates with two cases of postoperative radial nerve neuropraxia that recovered satisfactorily. Gallucci ${ }^{13}$ shows again the advantages of the posterior approach specifically in patients with compromise of the distal third of the humerus; his series of 21 patients presented successful consolidation in $100 \%$, recovery of functional mobility arches and adequate DASH and Constant scale results, with a single case of radial apraxia that recovered spontaneously. ${ }^{14,15}$

\section{Conclusion}

The results of this series of cases show us how the posterior minimally invasive technique with an anatomical implant is a good choice for the management of fractures of the distal humeral shaft, providing safety when performing direct control of the radial nerve, presenting low rates of complications. With complete control of the alignment in the anteroposterior plane and allowing technical skills and better distal fixation with the type of humerus plate used.

\section{Acknowledgments}

None.

\section{Conflicts of interest}

The authors declare there are no conflicts of interest.

\section{Funding}

None.

\section{References}

1. Tytherleigh-Strong G, Walls N, McQueen MM. The epidemiology of humeral shaft fractures. J Bone Joint Surg Br. 1998;80(2):249-253.

2. Ruedi T, Murphy WM. AO Principles of Fracture Management. StuttgartNew York: Thieme; 2000.

3. Igbigbi PS, Manda K. Epidemiology of humeral fractures in Malawi. Int Orthop. 2004;28(6):338-341.

4. Zagorski JB, Jennings JJ, Burkhalter WE. Comminuted intraarticular fractures of the distal humeral condyles. Surgical vs. nonsurgical treatment. Clin Orthop Relat Res. 1986;(202):197-204.

5. Robinson CM, Hill RM, Jacobs N. Adult distal humeral metaphyseal fractures: epidemiology and results of treatment. $J$ Orthop Trauma. 2003;17(1):38-47.

6. Livani B, Belangero WD, Castro de Medeiros R. Fractures of the distal third of the humerus with palsy of the radial nerve: management using minimally-invasive percutaneous plate osteosynthesis. J Bone Joint Surg Br. 2006;88(12):1625-1628. 
7. Kobayashi M, Watanabe Y, Matsushita T. Early full range of shoulder and elbow motion is possible after minimally invasive plate osteosynthesis for humeral shaft fractures. J Orthop Trauma. 2010;24(4):212-216.

8. Apivatthakakul T, Phornphutkul C, Laohapoonrungsee A, et al. Less Invasive Plate Osteosynthesis in Humeral Shaft Fractures. Oper Orthop Traumatol. 2009;21(6):602-613.

9. Livani B, Belangero W. Bridging plate osteosynthesis of humeral shaft fractures. Injury. 2004;35(6):587-595.

10. Gallucci G, Boretto J, Vujovich A, et al. Posterior Minimally Invasive Plate Osteosynthesis for Humeral Shaft Fractures. Tech Hand Up Extrem Surg. 2014;18(1):25-30.

11. Hervás MT, Navarro Collado MJ, et al. Spanish version of the DASH questionnaire. Cross-cultural adaptation, reliability, validity and responsiveness. Med Clin (Barc). 2006;127(12):441-447.
12. Zhiquan A, Bingfang $Z$, Yeming W. Minimally invasive plating osteosynthesis (MIPO) of middle and distal third humeral shaft fractures. J Orthop Trauma. 2007;21(9):628-633.

13. Balam KM, Zahrany AS. Posterior percutaneous plating of the humerus. Eur J Orthop Surg Traumatol. 2014;24(5):763-768.

14. Gallucci GL, Boretto JG, Alfie VA, et al. Posterior minimally invasive plate osteosynthesis (MIPO) of distal third humeral shaft fractures with segmental isolation of the radial nerve. Chir Main. 2015;34(5):221-226.

15. Gallucci G, Vujovich A, Boretto J, et al. Minimally invasive technique by posterior approach for the treatment of diaphyseal fractures of the humerus. Rev Asoc Argent Ortop Traumatol. 2013;78(2):64-73. 